\title{
Estrutura de capital, dinâmica da indústria e desempenho financeiro. a construção de um modelo de análise das firmas no Brasil
}

\section{Capital structure, industry dynamics and financial performance. the construction of a model of firm analysis in Brazil}

\author{
GEORGIA SAIANI MENDES* \\ DAVID FERREIRA LOPES SANTOS **
}

\section{RESUMO}

Este estudo analisa a relação do desempenho financeiro e da dinâmica da indústria com a estrutura de capital das empresas brasileiras, a partir da combinação de duas amplas fontes de dados secundários no período de 1999 a 2014. A base de dados conta com informações de 995 empresas em média para cada ano, cuja análise ocorreu por meio da modelagem por equações estruturais como forma de modelar, ao nível exploratório, as relações existentes entre as variáveis endógenas (desempenho) e variáveis exógenas (dinâmica da indústria) na estrutura de capital. Observa-se que as variáveis de desempenho apresentaram relação negativa e significativa com a estrutura de capital e, por sua vez, as variáveis da dinâmica da indústria apresentaram significância na metade do tempo estudado e indicaram associação positiva com o endividamento. Os resultados demonstram que o endividamento é influenciado por variáveis exógenas e endógenas às firmas, sendo os fatores internos os mais significativos. Não obstante, empresas com melhores desempenhos são aquelas

* Universidade Estadual Paulista "Júlio de Mesquita Filho" (UNESP), Bolsista de Iniciação Científica FAPESP e Graduada em Administração de Empresas pela Universidade Estadual Paulista "Júlio de Mesquita Filho". georgia_smendes@hotmail.com .

* Universidade Estadual Paulista "Júlio de Mesquita Filho" (UNESP). Pós Doutor e Doutor em Administração de Empresas pela Universidade Presbiteriana Mackenzie. Professor Assitente Doutor na UNESP - FCAV Jaboticabal - SP junto ao Departamento de Economia, Administração e Educação. david.lopes@fcav.unesp.br . 
que tendem a exibir os menores níveis de endividamento, o que aproxima a realidade brasileira da Pecking Order Theory.

palavras-chave: endividamento. pecking order. equações estruturais. rentabilidade. trade-off theory. volatilidade de mercado.

\section{ABstract}

This study analyzes the relationship of financial performance and industry dynamics with the capital structure of Brazilian companies, from the combination of two large secondary data sources from 1999 to 2014. The database has information from 995 companies (average) for each year, whose analysis took place through the structural equations modeling as a way of modeling, at the exploratory level, the relationships between the endogenous variables (performance) and exogenous variables (industry dynamics) in the capital structure. It is observed that the performance variables presented a negative and significant relationship with the capital structure, and, on the other hand, the variables of the industry dynamics presented significance in half the time studied and indicated a positive association with the indebtedness. The results demonstrate that the capital structure is influenced by exogenous and endogenous variables to the firms, being the internal factors the most significant. Nevertheless, companies with better performance are those that tend to present the lowest levels of indebtedness, which brings the Brazilian reality of Pecking Order Theory closer.

Key-words: Indebtedness. Pecking Order. Structural Equations. Profitability. Trade-off Theory. Market Volatility.

\section{INTRODUÇÃo}

As bases teóricas que suportam as decisões que envolvem a estrutura de capital das empresas e os seus reflexos no desempenho e no valor destas remontam ao ensaio de Durand (1952), quando a perspectiva acadêmica e empresarial na ocasião assinalava que as empresas buscavam um nível ótimo de endividamento como forma de maximizar o valor da empresa por meio da redução do custo médio de captação (PEROBELLI e FAMÁ, 2003; ASSAF NETO, 2014; SANTOS e FARINELLI, 2015).

Esse paradigma foi contrastado com a teoria da irrelevância da estrutura de capital de Modigliani e Miller (1958 e 1963), que alçou 
novos postulados às Finanças Corporativas, sendo considerados, inclusive, como trabalhos seminais em estrutura de capital, em razão da formalização quantitativa (ALVES e FERREIRA, 2011; PHILLIPS e SIPAHIOGLU, 2004; BRITO e LIMA, 2005; MARCON et al., 2007).

A evolução das pesquisas nesse campo do conhecimento ainda não encontrou uma corrente proeminente, de modo que novas alternativas para explicar as decisões que envolvem o endividamento das firmas foram alçadas. Destacam-se a Pecking Order Theory (MYERS, 1984; MYERS e MAJLUF, 1984; TITMAN e WESSELS, 1988; FRANK e GOYAL, 2003), Trade off Theory (DANG, KIM, e SHIN, 2014; JENSEN e MECKLING, 1976) e Agency Theory (WILLIAMSON, 1985), sendo todas oriundas de uma fonte comum, qual seja, a assimetria informacional entre as partes interessadas; sendo essa questão, tratada de forma neutra nos trabalhos de Modigliani e Miller em razão da assunção da existência de mercados perfeitos (BRITO e LIMA, 2005; MEDEIROS e DAHER, 2008; KAYO e KIMURA, 2011; GRAHAM e LEARY, 2011).

A ausência de um consenso teórico sobre os fatores determinantes da estrutura de capital das empresas torna este tema, igualmente, um dos mais tradicionais e relevantes para a atualidade das empresas (WONG, 2015).

Em paralelo, outras pesquisas empenharam-se em avaliar a influência da dinâmica da indústria na formação e dimensão do endividamento ao nível da firma (HARRIS e RAVIV, 1991; MANN e SICHERMAN, 1991; BALAKRISHNAN e FOX, 1993; SIMERLY e LI, 2000; MIGUEL e PINDADO, 2001; NOULAS e GENIMAKIS, 2011; BARCLAY, HEITZMAN e SMITH, 2013; CHUNG, NA e SMI$\mathrm{TH}, 2013)$. No entanto, a corrente majoritária das pesquisas foca fatores específicos da empresa e não considera questões associadas à indústria ou mesmo ao país em que está inserida (SIMERLY e LI, 2000; TUDOSE, 2012; SANTOS e FARINELLI, 2015).

Coelho et al. (2013) e Santos e Farinelli (2015), em pesquisa bibliométrica sobre estrutura de capital, verificaram que as pesquisas nesse tema, quando o objeto de análise é a firma, envolvem amplas amostras ou estudos em setores específicos. No entanto, poucos estudos analisam a estrutura de capital considerando amostras amplas e nestas as diferenças setoriais entre elas. 
Em tempo, os resultados das pesquisas realizadas no Brasil sinalizam para uma aderência do comportamento das firmas nacionais para a Pecking Order Theory (CARVALHAL e LEAL, 2013; CORREA, BASSO e NAKAMURA, 2013; FORTE, BARROS e NAKAMURA, 2013), ao contrário das evidências observadas no levantamento de Graham e Leary (2011) e Santos e Farinelli (2015), que identificaram maior aderência à Trade-off Theory nas pesquisas empíricas internacionais.

Santos e Farinelli (2015) apontam que os estudos mais amplos em número de setores e com séries históricas mais longas são as principais referências na área. No Brasil, há uma dificuldade em construir "painéis" desse tipo em função da limitação das bases de dados disponíveis, com efeito, os estudos setoriais são mais restritos.

Assinalam-se, contudo, estudos já realizados com amostras "privadas" em setores específicos, que admitiram a existência de diferenças na formação do endividamento, em função, da dinâmica e características do setor (GOMES e SANTOS, 2014; SANTOS et al., 2014); essas pesquisas, para a realidade brasileira, reportaram diferenças nas variáveis que explicam o endividamento das empresas, o que sugere a possibilidade de condições setoriais influenciarem no nível de endividamento das empresas.

Por isso, este estudo posiciona-se na discussão teórica que envolve a tríade endividamento, desempenho e dinâmica da indústria ainda em conformação e sem estudos empíricos de larga amplitude para a realidade brasileira. Portanto, a principal contribuição deste estudo é avaliar a dinâmica de 21 setores industriais brasileiros e o desempenho alcançado pelas empresas que o formam, de modo a entender o impacto que essas variáveis exercem na formação da estrutura de capital das firmas.

Desta forma, a originalidade deste estudo justifica-se pelos seguintes fatores:

a) Combinar na análise da estrutura de capital os fatores internos e externos à empresa, sendo que as variáveis observáveis poderão evidenciar variáveis não observadas, que poderão contribuir para uma melhor explicação da estrutura de capital das empresas.

b) Utilizar a análise por meio da modelagem de equações estruturais desses dois construtos (internos e externos) na estrutura 
de capital, sendo essa abordagem ainda totalmente nova para o tema no Brasil.

Para alcançar os objetivos deste estudo, o trabalho está organizado em mais quatro seções após esta introdução. A seção seguinte traz o referencial teórico sobre estrutura de capital em que se apresenta as principais correntes e trabalhos empíricos recentes relacionados com o tema deste estudo. A terceira seção apresenta os materiais e métodos que permitiram a construção da base de dados e o desenvolvimento dos resultados. A quarta seção apresenta os resultados e a discussão destes com a literatura. As considerações finais do estudo são destacadas na quinta seção, bem como, sugestões para trabalhos futuros. As referências encerram o trabalho.

\section{FUNDAMENTOS TEÓRICOS}

\subsection{Estrutura de capital}

A maneira pela qual as empresas compõem seu endividamento é um tema muito debatido na área de finanças, e, por conseguinte, a utilização de capital próprio e de terceiros é o foco de discussão entre os administradores financeiros (ASSAF NETO, 2014).

Existem correntes preponderantes sobre o assunto, como a teoria da irrelevância, defendendo que a estrutura de capital da empresa não é significativa para o financiamento de projetos, bem como, as teorias que consideram a estrutura de capital preponderante, avaliando que a estrutura de capital possui impacto na avaliação dos investimentos (CORREA, BASSO, NAKAMURA, 2013; MODIGLIANI e MILLER, 1958; MYERS, 1984).

Myers (2001) afirma que não existe uma "teoria universal" para a escolha do endividamento das empresas, somente teorias condicionais que podem auxiliar na escolha da estrutura de capital adequada. Essa situação deve-se às especificidades e características intrínsecas de cada empresa (BALAKRISHANAN e FOX, 1993).

Perante tantas discussões, serão apresentadas as teorias preponderantes no meio acadêmico sobre estrutura de capital e financiamento. 


\subsubsection{Pensamento Tradicional}

A perspectiva convencional entendia que a estrutura de capital exercia influência no valor da empresa, pois o custo da dívida (Kd) apresentaria variações marginais diferentes ao custo do capital próprio (Ke) (DURAND, 1952).

O capital próprio é a fonte de recursos com maior risco na estrutura patrimonial da empresa, assim, a substituição deste por capital de terceiros possibilitaria a redução do custo médio ponderado de capital (Weigthed Average Capital Costing - WACC). No entanto, a substituição encontraria um limite, em função das diferenças na evolução marginal dos Ke e $\mathrm{Kd}$, segundo o grau de endividamento. Nessa corrente, entendia-se que a partir de determinado grau de alavancagem a variação do $\mathrm{Kd}$ seria maior que o Ke, tornando a função quadrática, sendo a derivada o vértice da função e, sendo assim, o nível ótimo de endividamento (ASSAF NETO, LIMA e DE ARAÚJO, 2008; ASSAF NETO, 2014; TOMAZONI e MENEZES, 2002). A equação do custo médio ponderado de capital é discriminada na Fórmula 01.

$$
W A C C=\frac{E}{D+E} \cdot K e+\frac{D}{D+E} \cdot K d \cdot(1-I R)
$$

Sendo E o valor do patrimônio líquido, D o valor das dívidas, $\mathrm{K}_{\mathrm{e}} \mathrm{o}$ custo de capital próprio, $\mathrm{K}_{\mathrm{d}} \mathrm{o}$ custo de capital de terceiros, e IR a alíquota de imposto de renda.

\subsubsection{Teoria da irrelevância}

Modigliani e Miller (1958) refutaram o pensamento convencional ao demonstrar que o valor de uma empresa deveria ser função da qualidade dos seus ativos em gerar caixa e a taxa de desconto teria de ser aquela que representasse o risco dos ativos, independente da sua fonte. Nessa construção, os autores (MM) formularam duas proposições que tornaram esta obra um marco na moderna teoria das finanças.

No entanto, as bases que suportaram a teoria da irrelevância assumiram proposições que não se enquadravam ao mundo "real", pois não consideravam o efeito da dedutibilidade do Imposto de Renda da despesa financeira e admitiam que as empresas existiam 
em mercados eficientes, onde os custos de transação são irrelevantes, todos os agentes dispõem das mesmas estruturas e fontes de capital e as informações no mercado são simétricas entre todos os envolvidos.

Em razão da restrição do efeito de redução do pagamento de tributos com o uso da dívida, MM em 1963 corrigiram o trabalho de 1958, ao admitir que o valor de mercado de uma empresa computaria o valor presente do benefício fiscal. Segundo Assaf Neto (2014), a Equação 02 representa a fórmula do valor de mercado de uma empresa alavancada ancorada no modelo de MM:

$$
V_{L}=\frac{\text { Fluxos de Caixa Operacionais }}{K_{0}}+(I R \times P)
$$

De acordo com a fórmula, a parcela de fluxo de caixa operacional dividido pelo $\mathrm{K}_{0}$ representa o valor de uma empresa completamente pelo capital próprio, e a multiplicação da alíquota do imposto de renda (IR) com o passivo $(\mathrm{P})$ demonstraria o valor presente do benefício fiscal (ASSAF NETO, 2014).

Complementando a consideração dos impostos, Nakamura et al. (2007) afirmam:

À medida que se considera um mercado em que há impostos sobre o lucro das empresas, chega-se facilmente à conclusão de que as empresas deveriam trabalhar com grandes proporções de dívidas, por conta da vantagem fiscal decorrente do fato de que os juros, que remuneram as dívidas, são dedutíveis para fins de imposto de renda, o que não acontece com os fluxos de caixa pagos para os acionistas, principalmente os dividendos (NAKAMURA et al., 2007, p. 74).

\subsubsection{Teorias Decorrentes da Assimetria de Informação}

A teoria do Trade-off de Myers (1984) assume que para a empresa alcançar a estrutura de capital ótima, ela deve considerar os custos e benefícios do endividamento. Para tanto, ela necessita equilibrar os benefícios fiscais de juros com os custos de falência, alternando entre utilizar recursos internos e externos até o ponto de maximização do valor da empresa. Mais especificamente, a teoria sustenta o fato de que as empresas contraem endividamento até o 
momento em que o valor marginal dos benefícios fiscais é balanceado pelo aumento no valor presente de custos de dificuldades financeiras possíveis de acontecer (MYERS, 2001).

As dificuldades financeiras abrangem os custos de falência, de mudanças na organização, bem como, o custo de agência, que é aquele existente quando a empresa levanta dúvidas quanto à sua possibilidade de solvência perante as dívidas (MYERS, 2001).

Em contraponto, Handoo e Sharma (2014) defendem que o trade-off mais expressivo dentro de uma empresa é entre a flexibilidade financeira da firma e a disciplina fiscal, ultrapassando o conceito dos benefícios fiscais, caracterizando-o como fator insignificante na maioria das grandes empresas, a menos que tenham um nível de endividamento baixo.

A teoria do Pecking Order define uma hierarquia da preferência da empresa quanto aos seus endividamentos. Dessa forma, a organização deve optar primeiro por recursos internos (capital próprio), e em seguida recursos externos (capital de terceiros). A sequência de preferência quanto à utilização de recursos sustentada pelo modelo é respectivamente: utilização de recursos internos, geração de dívidas e, posteriormente, emissão de ações (MYERS, 1984).

O estudo de Öztekin (2015) ampara a ideia de que os lucros são um dos principais determinantes da estrutura de capital em todo o mundo, afirmando que organizações com maiores lucros tendem a ter menor índice de endividamento. Gómez, Castro e Ortega (2016) concordam e defendem que esse fato está ligado à teoria da Pecking Order, de modo que as empresas visam buscar recursos em seus próprios lucros, e não necessariamente gerando mais dívidas, como acentuado por Myers (1984). Isso pode ocorrer pelo fato de que empresas mais lucrativas tendem a possuir mais lucro retido, que é uma forma fácil e rápida de obtenção de recursos comparada com outros tipos de instrumentos financeiros (XU e LI, 2015).

\subsection{Dinâmica da Indústria}

A recorrência dos estudos sobre estrutura de capital envolve fatores internos à estrutura de capital, contudo, diferentes pesquisas reportam que fatores externos às empresas podem afetar a decisão quanto à alavancagem das empresas (NEJAD e WASIUZZAMAN, 
2015; ÖZTEKIN, 2015; KAYO e KIMURA, 2011), mesmo quando consideraram somente fatores internos (MATEEV, POUTZIOURIS e IVANOV, 2013).

Existem vários fatores exógenos às firmas que podem ser determinantes na estrutura de capital. Esses fatores podem estar associados a fatores do contexto econômico, político e social (MARTINS e TERRA, 2014; ÖZTEKIN, 2015; ANTONCZYK e SALZMANN, 2014) ou a variáveis relacionadas ao setor em que as empresas estão inseridas, como grau de competitividade, ciclo de vida, risco, entre outros (FOSU, 2013; VIEIRA, 2013; KAYO e KIMURA, 2011).

O setor que a empresa atua é um possível fator determinante da estrutura de capital das empresas, visto que empresas do mesmo setor têm características de trabalho que são relacionadas, com tendência a possuir estrutura de capital semelhante (ASSAF NETO, 2014).

A "dinâmica da indústria" compreende variáveis associadas as características setoriais como: condições econômicas do país (NEJAD e WASIUZZAMAN, 2015), concentração de mercado (FOSU, 2013), cultura organizacional (ANTONCZYK e SALZMANN, 2014; BHAIRD e LUCEY, 2014) e o risco do setor. Estes são alguns dos fatores externos às empresas e que podem influir na estrutura de capital das organizações.

Contudo, Nejad e Wasiuzzaman (2015) defendem o fato de que condições exógenas às empresas são fatores pouco preponderantes em relação à variação da estrutura de capital das firmas.

A munificência setorial é uma variável definida como a "disponibilidade de recursos no setor" (MARTINS e TERRA, 2014) e é calculada por meio da regressão do tempo com as vendas do setor no período de cinco anos, e, após, divide-se o coeficiente angular pela média das vendas do setor nesse mesmo período (KAYO e KIMURA, 2011; MARTINS e TERRA, 2014). Por intermédio dessa variável, é possível ver o reflexo da receita do setor e a sua influência na estrutura de capital das empresas. De acordo com Martins e Terra (2014) e Kayo e Kimura (2011), essa variável setorial possui uma associação negativa com a alavancagem, portanto, empresas que atuam em setores com maior disponibilidade de recursos precisam de menor quantidade de capital de terceiros em seus negócios, e 
também sugerem um maior crescimento das firmas, podendo resultar em maior lucratividade na indústria.

A respeito da lucratividade do setor, Santos et al. (2014) argumentam que a margem EBIT apresenta um efeito negativo no endividamento, sendo mediada pela variável de rentabilidade dos ativos, sustentando que a margem permite que as firmas com maiores lucros retenham mais recursos, e, dessa forma, adquiram menos dívidas. Fareed et al. (2014) defendem que, conforme o endividamento das empresas aumenta, a lucratividade diminui. Nesse aspecto, é possível denotar por meio de vários autores a preferência por mensurar a lucratividade pelos indicadores de rentabilidade, focando, nesse aspecto, fatores internos da firma (NEJAD e WASIUZZAMAN, 2015; MARTINS e TERRA, 2014; KAYO e KIMURA, 2011).

A respeito da concentração de mercado, é sustentado o fato de que empresas situadas em ambientes competitivos, ou seja, pouco concentradas, conseguem beneficiar-se significativamente do endividamento, enquanto as empresas não concentradas tendem a sofrer efeitos adversos do endividamento (FOSU, 2013). Por sua vez, também é denotado que a fatia de mercado que a empresa possui afeta o endividamento negativamente, de modo que organizações com grandes fatias de mercado tendem a limitar as suas dívidas (MITANI, 2014).

\subsection{Desempenho Financeiro}

A estrutura de capital possui influência significativa no desempenho das empresas, mostrando que é necessário os gestores estarem cientes desses impactos antes de modificarem suas dívidas e também que os investidores tenham consideração pelas dívidas das empresas antes de fazer algum investimento (SHEIKH e WANG, 2013). Dessa forma, foram observados estudos que analisam os impactos dos índices de desempenho na estrutura de capital.

Segundo Yogendrarajah e Thanabalasingam (2011), somente $5 \%$ da estrutura de capital das firmas são explicados pela margem operacional, contudo, os autores observaram que, se há um maior crescimento das dívidas, existe uma diminuição na margem. Santos e Rodrigues (2014) construíram um modelo no qual a variável dependente de desempenho (ROA) é testada pelas variáveis independentes, 
entre elas a margem operacional e a estrutura de capital. Por meio dos resultados, é possível denotar que a medida de desempenho sofre influência significativa de ambas as variáveis independentes, sendo que a estrutura de capital afeta negativamente o desempenho, e a margem operacional influi positivamente.

Kaveski et al. (2015) afirmam que não há associação expressiva entre rentabilidade do patrimônio líquido e o endividamento contábil, no entanto, existe evidência de que organizações com elevado retorno do investimento dos acionistas têm tendência a utilizar financiamento externo. Porém, Salim e Yadav (2012) discordam e mencionam que quanto maior o retorno do patrimônio líquido, tanto menor o endividamento, seja ele total, de curto ou longo prazo.

Sobre a rentabilidade medida pelo retorno do investimento Adi, Suhadak, Handayani e Rahayu (2013) assumem que o ROI é a medida que mais influi significativamente o desempenho financeiro das empresas de forma positiva. Contudo, é observado pelos autores que quanto maior o endividamento das empresas, tanto menor é o desempenho financeiro das mesmas. Em contraponto, no estudo de Turra, Vergini e Cunha (2015), o retorno sobre o investimento não teve confiabilidade suficiente para determinar o desempenho financeiro.

\subsection{Proposição do Modelo Empírico para a Pesquisa}

Os estudos internacionais apresentam amostras com grande quantidade de empresas e com lapso temporal estendido e, além disso, o método de regressão com dados em painel é a ferramenta estatística mais usual entre eles. Nesse aspecto, o emprego da técnica da Modelagem de Equações Estruturais poderá trazer uma nova perspectiva nesta análise, tendo em vista que nenhuma das pesquisas recentes identificadas utilizou esse método.

Em função da dicotomia dos estudos que envolvem fatores internos ou externos à firma, este estudo procura avaliar de forma exploratória um modelo empírico que congregue as duas dimensões internas e externas à firma. Nesse sentido, foram utilizadas as seguintes variáveis propostas no Quadro 1. 
Quadro 1 - Modelo empírico proposto para o estudo

\begin{tabular}{|c|c|c|c|}
\hline Variável & Fórmula & Hipótese & Referências \\
\hline END & $\begin{array}{l}\text { Passivo / } \\
\text { Ativo Total }\end{array}$ & $\begin{array}{l}\text { H1: Há relação entre } \\
\text { o Endividamento e as } \\
\text { demais variáveis. }\end{array}$ & $\begin{array}{l}\text { Dal Magro, Di Domenico } \\
\text { e Toledo Filho (2012); } \\
\text { Turra, Vergini e Da } \\
\text { Cunha (2015) }\end{array}$ \\
\hline$\Delta$ Receita & & $\begin{array}{l}\text { H2: Há relação negativa } \\
\text { entre a } \Delta \text { Receita e o } \\
\text { Endividamento. }\end{array}$ & Hoyos e Garzón (2015) \\
\hline $\begin{array}{l}\Delta \text { Lucro Ope- } \\
\text { racional }\end{array}$ & & $\begin{array}{l}\text { H3: Há relação negativa } \\
\text { entre a } \Delta \text { Lucro Opera- } \\
\text { cional e o END. }\end{array}$ & $\begin{array}{l}\text { Santos e Rodrigues } \\
\text { (2014); Adi, Suhadak, } \\
\text { Handayani e Rahayu } \\
\text { (2013) }\end{array}$ \\
\hline Concentração & & $\begin{array}{l}\text { H4: Há relação negativa } \\
\text { entre a concentração e o } \\
\text { Endividamento. }\end{array}$ & $\begin{array}{l}\text { Fosu (2013); Mitani } \\
\text { (2014); Martins e Terra } \\
(2014)\end{array}$ \\
\hline ROE & $\begin{array}{l}\text { Lucro Lí- } \\
\text { quido/ } \\
\text { Patrimônio } \\
\text { Líquido } \\
\end{array}$ & $\begin{array}{l}\text { H5: Há relação negativa } \\
\text { entre o ROE e o Endivi- } \\
\text { damento. }\end{array}$ & $\begin{array}{l}\text { Kaveski et al. (2015); } \\
\text { Salim e Yadav (2012); Dal } \\
\text { Magro, Di Domenico e } \\
\text { Toledo Filho (2012) }\end{array}$ \\
\hline ROI & $\begin{array}{l}\text { Lucro Ope- } \\
\text { racional/ } \\
\text { Investimen- } \\
\text { to }\end{array}$ & $\begin{array}{l}\text { H6: Há relação negativa } \\
\text { entre o ROI e o Endivi- } \\
\text { damento. }\end{array}$ & $\begin{array}{l}\text { Turra, Vergini e Cunha } \\
\text { (2015); Adi, Suhadak, } \\
\text { Handayani e Rahayu } \\
\text { (2013); }\end{array}$ \\
\hline $\begin{array}{l}\text { Margem Ope- } \\
\text { racional }\end{array}$ & $\begin{array}{l}\text { Lucro } \\
\text { Operacio- } \\
\text { nal/ Receita } \\
\text { Total }\end{array}$ & $\begin{array}{l}\text { H7: Há relação negativa } \\
\text { entre a Margem Ope- } \\
\text { racional e o Endivida- } \\
\text { mento. }\end{array}$ & $\begin{array}{l}\text { Santos e Rodrigues } \\
\text { (2014); Yogendrarajah e } \\
\text { Thanabalasingam (2011); } \\
\text { Perobelli e Famá (2003) }\end{array}$ \\
\hline Giro do Ativo & $\begin{array}{l}\text { Receita/Ati- } \\
\text { vo Total }\end{array}$ & $\begin{array}{l}\text { H8: Há relação entre } \\
\text { Giro do Ativo e o Endi- } \\
\text { vidamento. }\end{array}$ & $\begin{array}{l}\text { Santos e Rodrigues } \\
(2014)\end{array}$ \\
\hline
\end{tabular}

Fonte: elaboração dos autores

A adoção da variável variação do lucro operacional considerada como um aspecto setorial é uma abordagem não explorada pelo referencial teórico. Ela será tratada devido à importância de fatores individuais da firma que se sustentam por meio do lucro operacional como a margem operacional e o retorno do investimento e, dessa forma, 
será possível observar se o resultado operacional do setor influencia a forma pela qual as empresas se endividam (SANTOS e RODRIGUES, 2014; ADI, SUHADAK, HANDAYANI e RAHAYU; 2013).

A utilização da razão de concentração como mais um elemento para explicar a dinâmica da indústria é um ponto de inovação neste estudo, pois ainda não foi aplicada em modelos que trabalham com o relacionamento da dinâmica da indústria com a estrutura de capital.

\section{Metodologia}

A natureza da pesquisa realizada é exploratória, em razão da proposta de construção de um modelo de análise inédito para o fim proposto. Além disso, a perspectiva da pesquisa é quantitativa, tendo em vista que a coleta e a exploração dos dados se darão em conformidade com métodos quantitativos previstos para a sua análise.

\subsection{Material}

Esta pesquisa teve os seus dados coletados em duas fontes principais: Sistema Economática ${ }^{\circledR}$ e base privada “Balanços Patrimoniais". Os dados foram tabulados em planilhas eletrônicas do Excel $^{\circledR}$ e, dessa forma, se calcularam as variáveis.

As observações utilizadas são referentes ao período de 1998 a 2014, e, devido ao cálculo de variação de receita e lucro operacional, retornaram dados de 1999 a 2014. Para selecionar as empresas do estudo, foi estipulado um mínimo de 12 anos de dados completos disponíveis no período.

Os setores da amostra foram: Agricultura, Alimentos, Bebidas e Fumo, Cana, Couro e Calçados, Comércio Atacadista, Comércio Varejista, Eletrodomésticos, Equipamentos Elétricos, Farmacêutico, Logística, Madeiras e Móveis, Material Eletrônico, Mecânica, Metalurgia, Mineração, Minerais não metálicos, Papel e Celulose, Petróleo e Gás, Plástico e Borracha, e Têxtil. Totalizou-se 21 setores com média de 995 observações por ano.

Os indicadores necessários para a construção do modelo do estudo estão discriminados no Quadro 1.

Dessa forma, o modelo do trabalho está disposto na Figura 1. 
Figura 1 - Diagrama de caminhos para o modelo empírico proposto neste estudo.

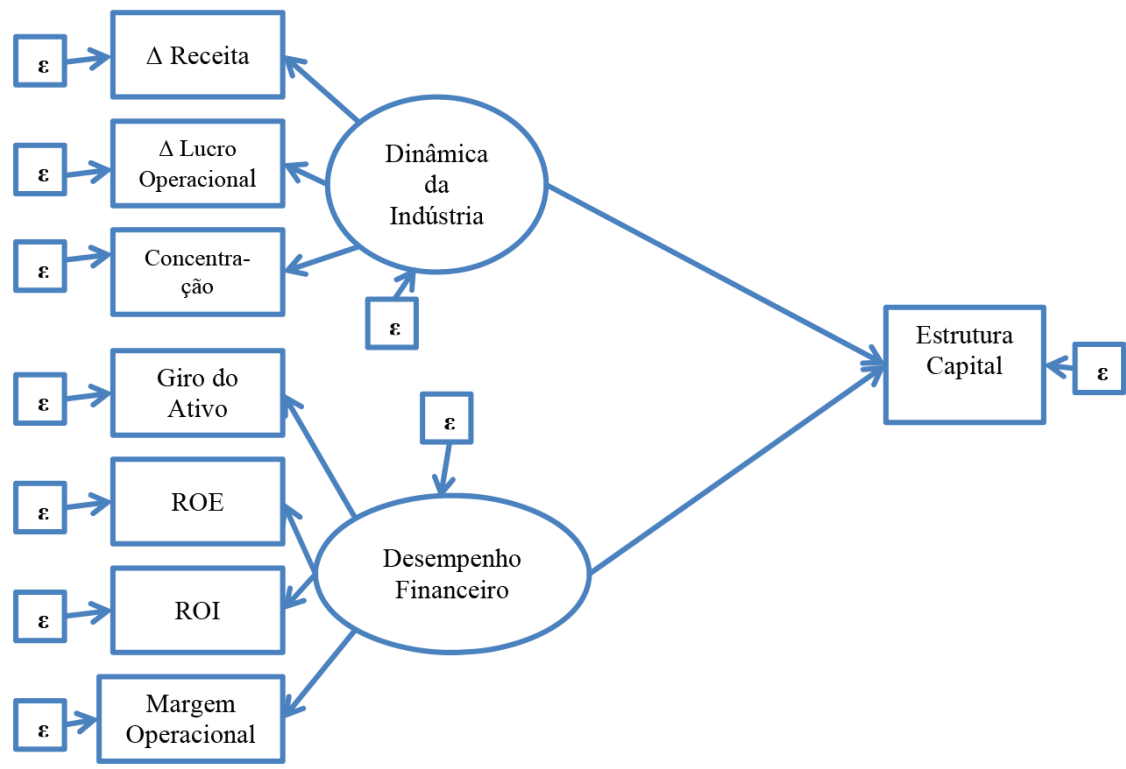

Fonte: elaboração dos autores

A fim de aumentar a normalidade das variáveis, foram utilizados dados padronizados, ou seja, aqueles que são calculados por meio da diferença da observação pela média da amostra e relação com o desvio padrão. Também foi feito o ajuste dos dados por intermédio da média e do cálculo do desvio padrão da amostra, sendo que dados que excediam o valor da média somados ou subtraídos de três desvios padrões foram substituídos pela média da amostra original, a fim de suprimir valores discrepantes da amostra que prejudicassem o comportamento dos resultados da mesma.

\subsection{Métodos}

O teste empírico para a amostra consolidada obedeceu a duas etapas: análise fatorial e análise por meio do modelo de equações estruturais. 
A análise fatorial, pela sua capacidade de resumir um universo de variáveis em fatores, cujo agrupamento depende do grau de intercorrelação entre as variáveis, conforme aponta Hair Jr. et al. (2005, p. 91):

Com a análise fatorial, o pesquisador pode primeiro identificar as dimensões separadas da estrutura e então determinar o grau em que cada variável é explicada por cada dimensão. Uma vez que essas dimensões e explicação de cada variável estejam determinadas, os dois principais usos da análise fatorial - resumo e redução dos dados - podem ser conseguidos. Ao resumir os dados, a análise fatorial obtém dimensões latentes, que quando interpretadas e compreendidas, descrevem os dados em um número muito menor de conceitos do que as variáveis originais. A redução dos dados pode ser conseguida calculando escores para cada dimensão latente e substituindo as variáveis originais pelos mesmos.

A utilização da análise fatorial neste estudo, a priori, teve por objetivo verificar se os indicadores organizados na Figura 1 correspondem às variáveis latentes previstas na teoria, sendo, portanto, uma técnica exploratória com a finalidade de confirmar, aperfeiçoar ou invalidar os construtos idealizados.

Hair Jr. et al. (2005) recomendam para um melhor ajuste do modelo que seja feito o teste Barlett de esfericidade e o teste KaiserMeyer-Olkin (KMO) que compara a magnitude do coeficiente de correlação observado com a magnitude do coeficiente de correlação parcial.

A técnica estatística para analisar o modelo de análise proposto é a modelagem por equações estruturais - SEM - (Structural Equation Modeling), pois esta “é particularmente útil quando uma variável dependente se torna independente em subsequentes relações de dependência (...) a formulação básica da SEM em termos de equações é" (HAIR Jr. et al., 2005, p. 476): 


$$
\begin{aligned}
& Y_{1}=X_{1}+X_{\mathrm{2}}+X_{\mathrm{B}}+\ldots+X_{1 n} \\
& Y_{2}=X_{2}+X_{2}+X_{3}+\ldots+X_{2 n} \\
& Y_{m}=X_{m 1}+X_{m 2}+X_{m 3}+\ldots+X_{m}
\end{aligned}
$$

Ainda em Hair Jr. et al. (2005, p. 466), pode-se encontrar as justificativas para o uso das equações estruturais:

a) Fornece um método direto para lidar com múltiplas relações simultaneamente enquanto entrega significância estatística;

b) Habilidade para avaliar as relações em âmbito geral e fornecer uma transição da análise explanatória para análise confirmatória;

c) Habilidade de empregar múltiplas medidas de um conceito em uma maneira semelhante à análise fatorial.

A utilização da SEM permite analisar no próprio modelo a constituição e o efeito de variáveis latentes (não observáveis). As variáveis latentes melhoram a estimação estatística, explicando com mais precisão os conceitos teóricos, isto, porque um coeficiente de regressão é formado por dois elementos a parte verdadeira e a confiável. O elemento verdadeiro é a parte precisa da relação existente entre as variáveis, enquanto que o confiável é um grau em que a variável independente é livre de erro, pois se sabe que é impossível estimar um modelo perfeito (HAIR Jr. et al., 2005).

Os trabalhos empíricos e teóricos listados na bibliografia sustentam o modelo proposto e indicam que existe relação de causalidade entre as variáveis latentes dinâmica da indústria, desempenho financeiro e estrutura de capital.

Encontrou-se apenas um estudo relacionado com estrutura de capital que utilizou a SEM (LIM, DAS e DAS, 2009), porém associado com estratégia empresarial e não diretamente com a dinâmica da indústria, o que aumenta a originalidade da proposta deste estudo tanto ao nível nacional quanto internacional.

A utilização da modelagem de equações estruturais permite captar o peso de cada variável explanatória na estrutura de capital, considerando, ainda, as relações entre as próprias variáveis independentes e dependentes. Em razão da teoria de estrutura de capital ainda não ter um construto robusto o suficiente para explicar os fatores que o determinam, esta pesquisa contribui com o desafio de modelar as variáveis que determinam a estrutura de capital. 
A necessidade de entregar um modelo estatisticamente ajustado é fundamental para a validação dessa tese e dos resultados por ela propostos, em especial, no uso SEM. Hair Jr. et al (2005) ressaltam que os resultados da SEM devem ser analisados primeiramente pela verificação da existência de estimativas transgressoras, isto é, se os coeficientes padronizados excedem ou estão muito próximos a 1,0; se existem variâncias negativas ou não significantes de erro para qualquer construto, ou se há erro padrão muito grande associado com as variáveis exógenas.

Além da necessidade de se verificar a existência de estimativas transgressoras, existem diversos testes que devem ser analisados a fim de se verificar o ajuste do modelo. Assim sendo, definiu-se a utilização dos testes no Quadro 2, em conformidade com o Hair Jr. et al. (2005), Kelloway (1998) e Schumacker e Lomax (2004):

\section{Quadro 2 - Testes de Ajuste do Modelo SEM}

\begin{tabular}{|l|l|l|}
\hline Medidas de Qualidade de Ajuste & Análise & $\begin{array}{l}\text { Nível de Ajuste } \\
\text { Aceitável }\end{array}$ \\
\hline $\begin{array}{l}\text { Estatística qui-quadrado de razão } \\
\text { de verossimilhança }\left(x^{2}\right)\end{array}$ & $\begin{array}{l}\text { Teste de significância } \\
\text { fornecido. }\end{array}$ & Entre $1 \%$ a $10 \%$ \\
\hline $\begin{array}{l}\text { Índice de Qualidade de Ajuste } \\
(\text { GFI })\end{array}$ & $\begin{array}{l}\text { Valores maiores indicam } \\
\text { melhor ajuste. }\end{array}$ & $\begin{array}{l}\text { Deve ser maior } \\
\text { que 0,90 }\end{array}$ \\
\hline $\begin{array}{l}\text { Índice de Qualidade de Ajuste } \\
\text { (AGFI) }\end{array}$ & $\begin{array}{l}\text { Medida de Ajuste incre- } \\
\text { mental. Valores maiores } \\
\text { indicam melhor ajuste. }\end{array}$ & $\begin{array}{l}\text { Nível recomenda- } \\
\text { do }>\text { que 90 }\end{array}$ \\
\hline Qui-quadrado Normado & $\begin{array}{l}\text { Razão entre o qui-qua- } \\
\text { drado e os graus de } \\
\text { liberdade. }\end{array}$ & $\begin{array}{l}\text { Limite inferior: } \\
1,0 \\
\text { Limite superior: } \\
5,0\end{array}$ \\
\hline $\begin{array}{l}\text { Raiz do Erro Quadrático Médio de } \\
\text { Aproximação (RMSEA) }\end{array}$ & $\begin{array}{l}\text { Diferença média por } \\
\text { grau de liberdade que } \\
\text { se espera ocorrer na po- } \\
\text { pulação, não na amostra }\end{array}$ & $\begin{array}{l}\text { Valores aceitáveis } \\
\text { abaixo de 0,10 }\end{array}$ \\
\hline
\end{tabular}

Fonte: Elaboração dos autores

\section{Discussão doS RESUlTAdos}

A Tabela 1 demonstra a média e o desvio padrão das variáveis, conforme os períodos observados. Com a análise dos dados, 
é possível afirmar que houve crescimento significativo da Razão de Concentração, atestando que as empresas tiveram aumento na participação de mercado de mais de $99 \%$ comparando o primeiro com o último ano estudado.

A média de endividamento das empresas no período é de $53,33 \%$, demonstrando que mais da metade dos recursos da empresa são oriundos de capital de terceiros. Já a Variação do Lucro Operacional possui médias predominantemente negativas, indicando que o lucro das empresas brasileiras decaiu.

A Variação do Lucro Operacional em alguns anos tem um desvio padrão alto, podendo gerar distorções nas médias nos períodos em que sua dispersão é maior, já que os dados estão pouco estáveis.

A Razão de Concentração apresenta o menor desvio padrão e demonstra que ao longo do tempo não houve alterações significativas na estrutura de concentração dos setores, sendo que, para as demais variáveis da dinâmica da indústria, observa-se um maior grau de volatilidade no lucro operacional e na receita.

A Tabela 2 reporta a análise fatorial das variáveis da Figura 1 como forma de verificar se as variáveis propostas demonstram a interdependência prevista no modelo. Como pode-se observar a análise foi realizada para cada ano e foram mantidas somente as cargas fatoriais superiores a 0,4 . 


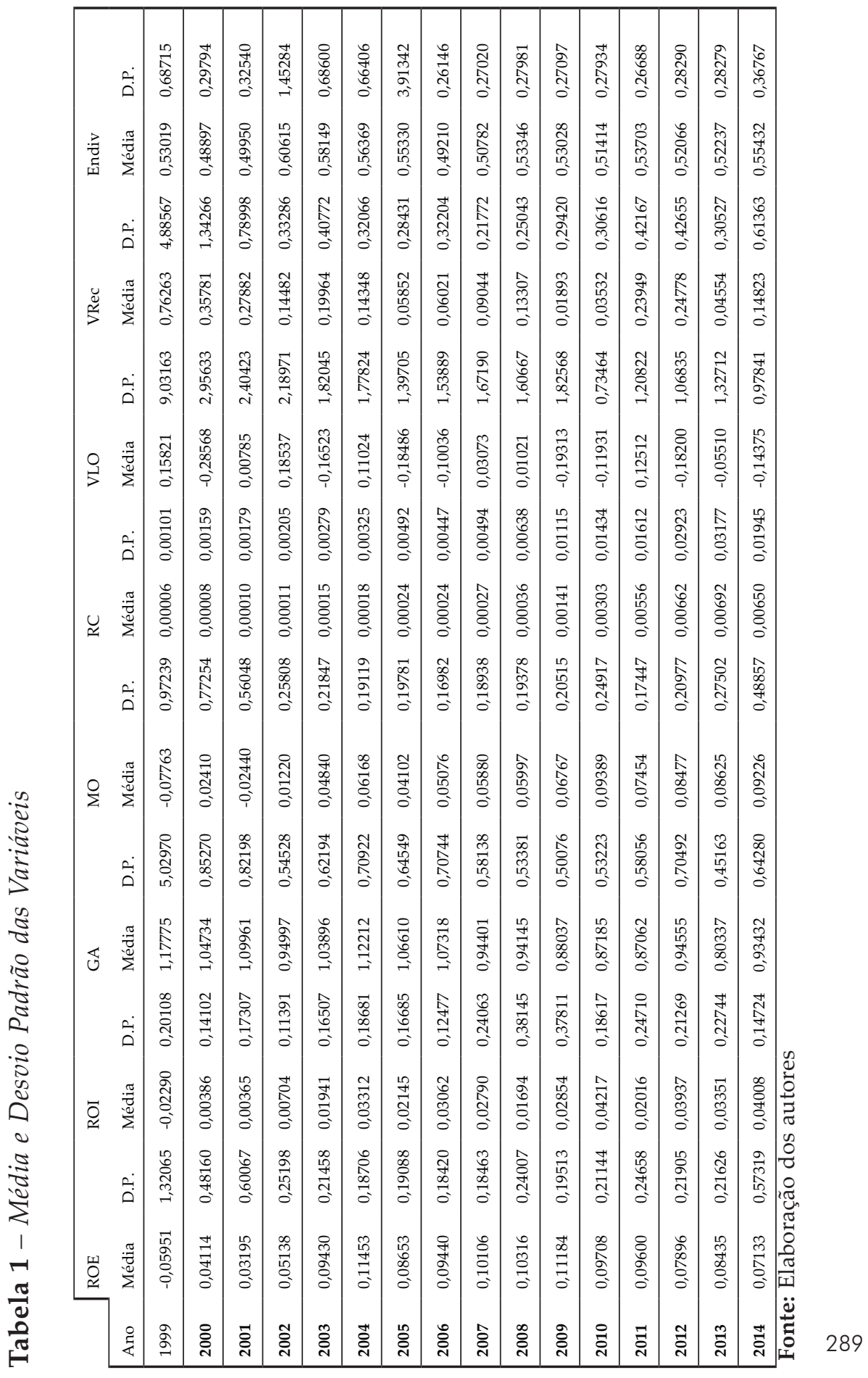




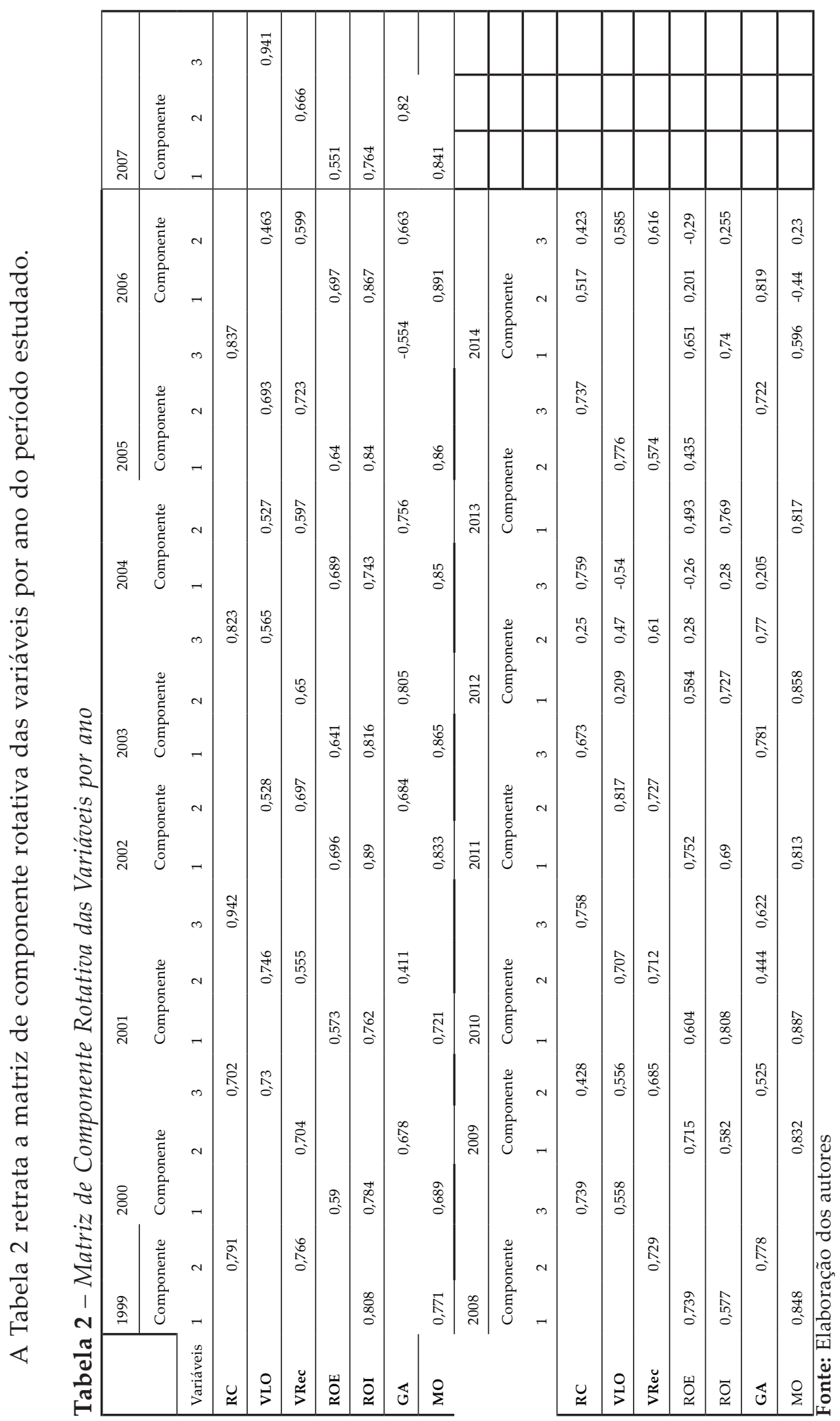


Todas as análises fatoriais reportaram ajustes adequados para fins de avaliação dos resultados, a Tabela 3 apresenta os resultados dos testes KMO e esfericidade de Barlett, além de apresentar o total de variância explicada pelos dois fatores.

Tabela 3 - Testes KMO e de esfericidade de Barlett

\begin{tabular}{l|l|l|l}
\hline Ano & KMO & Barlett & Variância Total \\
\hline 1999 & 0,520 & 322,695 & $39,667 \%$ \\
\hline 2000 & 0,554 & 264,940 & $52,274 \%$ \\
\hline 2001 & 0,600 & 314,859 & $52,597 \%$ \\
\hline 2002 & 0,626 & 1113,118 & $46,812 \%$ \\
\hline 2003 & 0,640 & 826,591 & $59,215 \%$ \\
\hline 2004 & 0,655 & 735,592 & $45,469 \%$ \\
\hline 2005 & 0,683 & 950,577 & $60,033 \%$ \\
\hline 2007 & 0,658 & 1253,127 & $47,288 \%$ \\
\hline 2008 & 0,609 & 546,341 & $57,142 \%$ \\
\hline 2009 & 0,610 & 543,412 & $57,002 \%$ \\
\hline 2011 & 0,552 & 325,623 & $40,819 \%$ \\
\hline 2012 & 0,577 & 451,862 & $60,677 \%$ \\
\hline 2013 & 0,563 & 222,732 & $59,033 \%$ \\
\hline 2014 & 0,571 & 519,699 & $58,377 \%$ \\
\hline & 0,555 & 402,810 & $56,691 \%$ \\
\hline & 0,513 & 190,823 & $52,346 \%$ \\
\hline
\end{tabular}

Fonte: Elaboração dos autores

O comportamento das matrizes de componente rotativa das variáveis acentua o agrupamento das variáveis: ROI, ROE e Margem Operacional, visto que elas aparecem quinze anos concentradas no primeiro componente, indicando a interdependência dessas métricas e a validação da sua utilização conjunta na variável latente Desempenho Financeiro, enquanto fator interno. Já o Giro do Ativo, que a princípio estaria incorporado nesse mesmo construto, demonstrou conexão com as variáveis de Dinâmica da Indústria, principalmente com a Variação da Receita.

A Dinâmica da Indústria, representada pela VLO, VRec e RC, apresentou pouca estabilidade na construção de seus componentes, 
devido à sua variabilidade de agrupamento entre as métricas predefinidas. A relação que pode ser evidenciada foi entre o VLO e a VRec, já que se mantiveram juntas em onze anos, demonstrando que são mais relevantes quando se referem à dinâmica da indústria.

Em função da proposição do modelo para a análise e da heterogeneidade da amostra, que é uma característica das empresas brasileiras, verifica-se que as variáveis propostas de fato se agrupam em fatores internos e externos, contudo, os indicadores internos demonstraram maior aproximação e repetição aos externos, sinalizando que podem existir outros indicadores que melhor definiriam a dinâmica da indústria ou mesmo que, em função das suas naturezas distintas, possam existir mais de uma variável latente que reflita os fatores externos.

Não obstante, mesmo utilizando outras variáveis que caracterizam o setor, os autores Martins e Terra (2015) afirmam que a variância de fatores internos à empresa representa aproximadamente onze vezes mais impacto na alavancagem do que variáveis setoriais das empresas brasileiras. Kayo e Kimura (2011) acentuam que realmente a firma representa a maior parte da variância da estrutura de capital das empresas, contudo, desenvolveu modelos que sugerem que a indústria pode chegar a uma variância de $11,6 \%$ no endividamento.

Decidiu-se, nesta pesquisa, para a análise do modelo, pela manutenção da estrutura dos construtos previstos no modelo teórico, pois conforme assinala a literatura, a construção do modelo deve ter, antes de tudo, o suporte teórico. Como há razão para entender que os fatores externos podem auxiliar na explicação do endividamento da firma, manteve-se a proposta das variáveis e as relações previstas inicialmente.

A Tabela 4 apresenta os estimadores padronizados das equações estruturais em cada ano. Os resultados referentes aos ajustes do modelo estão organizados na Tabela 4. 
Tabela 4 - Estimadores Padronizados do Modelo Empírico

\begin{tabular}{|c|c|c|c|c|c|c|c|c|c|}
\hline Ano & ROI & ROE & $\mathrm{MO}$ & GA & DF & $\mathrm{RC}$ & VLO & VRec & DI \\
\hline 1999 & $0,99^{* * *}$ & $0,14^{* * *}$ & $0,38^{* * *}$ & 0,05 & $-0,34^{* * *}$ & 0,59 & $0,13^{* *}$ & $0,53^{* *}$ & 0,02 \\
\hline 2000 & $1,10^{* * *}$ & $0,28^{* * *}$ & $0,25^{* * *}$ & $0,11^{* * *}$ & $-0,26^{* * *}$ & 0,04 & 1,00 & 0,04 & $-0,03$ \\
\hline 2001 & $0,73^{* * *}$ & $0,29^{* * *}$ & $0,55^{* * *}$ & $0,18^{* * *}$ & $-0,4^{* * *}$ & 1,00 & 0,00 & $-0,01$ & 0,03 \\
\hline 2002 & $0,98^{* * *}$ & $0,51^{* * *}$ & $0,66^{* * *}$ & $0,12^{* * *}$ & $-0,12^{* * *}$ & 0,01 & $0,11^{* * *}$ & $1,00^{* * *}$ & $-0,06^{* *}$ \\
\hline 2003 & $1,08^{* * *}$ & $0,29^{* * *}$ & $0,50^{* * *}$ & $0,10^{* * *}$ & $-0,46^{* * *}$ & 0,02 & $0,08^{* * *}$ & $1,00^{* *}$ & $0,05^{* *}$ \\
\hline 2004 & $0,72^{* * *}$ & $0,54^{* * *}$ & $0,65^{* * *}$ & $0,17^{* * *}$ & $-0,32^{* * *}$ & 0,00 & $0,12^{* * *}$ & 1,00 & 0,04 \\
\hline 2005 & $0,70^{* * *}$ & $0,54^{* * *}$ & $0,79^{* * *}$ & 0,18 & $-0,04$ & $0,06^{* *}$ & $0,18^{* * *}$ & $0,99^{* *}$ & $-0,06^{* *}$ \\
\hline 2006 & $0,87^{* * *}$ & $0,55^{* * *}$ & $0,80^{* * *}$ & $0,16^{* * *}$ & $-0,26^{* * *}$ & $-0,01$ & $0,08^{* * *}$ & $1,00^{* * *}$ & $0,13^{* * *}$ \\
\hline 2007 & $0,54^{* * *}$ & $0,45^{* * *}$ & $0,75^{* * *}$ & $0,16^{* * *}$ & $-0,28^{* * *}$ & 0,01 & $0,11^{* * *}$ & $1,00^{* * *}$ & $0,09^{* * *}$ \\
\hline 2008 & $0,34^{* * *}$ & $0,58^{* * *}$ & $0,83^{* * *}$ & $0,12^{* * *}$ & $-0,03^{* * *}$ & 0,02 & $0,10^{* * *}$ & $1,00^{* *}$ & $0,07^{* *}$ \\
\hline 2009 & $0,07^{* * *}$ & $0,08^{* * *}$ & $-0,04^{* *}$ & 0,06 & $-0,01$ & $0,06^{*}$ & $0,18^{* * *}$ & 0,92 & 0,06 \\
\hline 2010 & $0,71^{*}$ & $0,44^{*}$ & $0,81^{*}$ & $0,09^{*}$ & $-0,24^{*}$ & 0,05 & $0,14^{* * *}$ & 1,00 & 0,00 \\
\hline 2011 & $0,47^{* * *}$ & $0,53^{* * *}$ & $0,80^{* * *}$ & $-0,01^{* * *}$ & $-0,19^{* * *}$ & 0,05 & 1,00 & $0,21^{* * *}$ & $-0,01$ \\
\hline 2012 & $0,43^{* * *}$ & $0,4^{* * *}$ & $0,95^{* * *}$ & $-0,06^{*}$ & $-0,19^{* * *}$ & 0,05 & $0,12^{* * *}$ & $0,99^{* *}$ & $0,06^{* *}$ \\
\hline 2013 & $0,05^{* * *}$ & $0,04^{* * *}$ & $-0,07^{* * *}$ & 2,20 & $-2,12$ & 0,07 & 0,01 & $0,09^{* * *}$ & 2,4 \\
\hline 2014 & $0,12^{* * *}$ & $0,08^{* *}$ & $-0,11^{* * *}$ & $1,00^{* * *}$ & $0,07^{* *}$ & 0,04 & $0,06^{* *}$ & $0,99^{* *}$ & $-0,07^{* *}$ \\
\hline
\end{tabular}

Nota: Níveis de significância: ${ }^{*}>90 \%{ }^{* *}>95 \%$; ${ }^{* *}>99 \%$.

Fonte: Elaboração dos autores

Verifica-se que a variável latente Desempenho Financeiro (DF), enquanto variável reflexiva das variáveis internas à firma (ROI, $\mathrm{ROE}, \mathrm{MO}$ e GA), apresentou influência negativa em todos os anos no endividamento, sendo que somente em três anos (2005, 2009 e 2013) essa influência não foi significativa. Esses resultados ratificam a perspectiva da pecking order para as empresas brasileiras, pois quanto melhor desempenho interno das empresas na geração e retenção de renda, tanto menor é o seu nível de endividamento (ÖZTEKIN, 2015; GÓMEZ, CASTRO e ORTEGA; 2016; MYERS, 1984). Também é importante assinalar que o lucro retido é uma forma fácil e rápida de obtenção de recursos comparando-se com outros tipos de instrumentos financeiros (XU e LI, 2015).

A Margem Operacional tem efeito positivo no Desempenho Financeiro, que, por conseguinte, tem influência predominantemente negativa no endividamento. Portanto, é possível afirmar que a MO 
possui associação negativa com a estrutura de capital das empresas, como acentuado por Yogendrarajah e Thanabalasingam (2011), e refutado por Santos e Rodrigues (2014).

Salim e Yadav (2012) corroboram com os fatores evidenciados na Tabela 7, mencionando que quanto maior o retorno do patrimônio líquido, tanto menor o endividamento, que em sua pesquisa foi segmentado em: total, de curto e longo prazo. Já Kaveski et al. (2015) consideraram o ROE sem associação expressiva com a estrutura de capital, sendo contrariados pelas evidências do presente estudo.

Os resultados desta pesquisa associam-se com os apontamentos de Adi, Suhadak, Handayani e Rahayu (2013), de que o ROI é a medida que mais influi significativamente no desempenho financeiro das empresas de forma positiva e também evidencia a relação negativa entre o DF e o endividamento das empresas, já que, quanto maior o endividamento das empresas, tanto menor é o desempenho financeiro das mesmas.

Destaca-se que todas as variáveis observáveis apresentaram influência positiva na formação do construto desempenho financeiro em praticamente todos os anos, somente o Giro do Ativo (GA) e a Margem Operacional (MO) apresentaram três e dois anos de reflexo negativo no desempenho financeiro (respectivamente). Não obstante, a significância estatística dos coeficientes ocorre em praticamente todos os anos para todas as variáveis.

Essa situação corrobora a importância dos fatores internos na formação do endividamento, inclusive, de forma mais contundente que os fatores externos, tendo em vista que a Dinâmica da Indústria só foi significativa na explicação do endividamento em 50\% do tempo analisado, e o grau de influência foi positivo em cinco anos e negativo nos outros três anos em que os coeficientes foram significativos (KAYO e KIMURA, 2011).

A alternância entre os efeitos positivos e negativos denota as estratégias de estrutura de capital das empresas frente às variações do mercado, principalmente tendo em vista que as variações de receita e do lucro operacional foram significativas na maioria dos anos analisados, enquanto que a razão de concentração só foi significativa em dois anos, o que não confirma a hipótese de que empresas em situações de mercado mais oligopolizado podem apresentar maiores 
ou menores níveis de endividamento (FOSU, 2013; MITANI, 2014). Nejad e Wasiuzzaman (2015) também reconheceram em seu estudo que a Concentração da Indústria não tem efeito significativo na estrutura de capital das firmas.

No entanto, o risco de cada mercado, mensurado pela volatilidade da receita e do lucro operacional, demonstra influência na variável Dinâmica da Indústria. Dessa forma, a perspectiva de que firmas com menor volatilidade em seus resultados, portanto, menor risco, podem obter menores taxas tendo maior acesso a endividamento, não é reafirmada devido à predominância dos estimadores positivos encontrados (PEROBELLI e FAMÁ, 2003).

Já nos anos 2002 e 2014, esse fato é observado, já que os estimadores são negativos em relação ao endividamento. Esse efeito pode ser decorrente das eleições no país, período no qual há uma incerteza econômica maior, favorecendo a redução do endividamento. Essa situação corrobora com estudos que procuram estudar variáveis ligadas ao país como determinantes de estrutura de capital (NEJAD e WASIUZZAMAN, 2015; KAYO e KIMURA, 2011).

Ademais, em 2008 o estimador da Dinâmica da Indústria foi significante, porém, entre 2009 e 2011 não há influência do construto no endividamento. Isso aponta para a segurança da utilização dos recursos internos da empresa em períodos de crise, focando recursos próprios em detrimento de recursos externos, conforme assinala a hierarquia das fontes de financiamento da pecking order (MYERS, 1984).

Na Tabela 8, apresentam-se os testes de ajuste RMR, GFI, AGFI e RMSEA para as equações estruturais cujos resultados são apresentados na Tabela 5 . 
Tabela 5 - Testes de Ajuste de Modelo

\begin{tabular}{|lllll|}
\hline Ano & RMR & GFI & AGFI & RMSEA \\
1999 & 0,020 & 0,996 & 0,993 & 0,000 \\
\hline 2000 & 0,035 & 0,990 & 0,982 & 0,034 \\
\hline 2001 & 0,035 & 0,987 & 0,976 & 0,044 \\
\hline 2002 & 0,044 & 0,983 & 0,969 & 0,051 \\
\hline 2003 & 0,083 & 0,942 & 0,895 & 0,106 \\
\hline 2004 & 0,071 & 0,946 & 0,902 & 0,103 \\
\hline 2005 & 0,051 & 0,977 & 0,958 & 0,063 \\
\hline 2006 & 0,063 & 0,962 & 0,931 & 0,084 \\
\hline 2007 & 0,063 & 0,959 & 0,927 & 0,085 \\
\hline 2008 & 0,073 & 0,953 & 0,915 & 0,093 \\
\hline 2009 & 0,015 & 0,908 & 0,834 & 0,144 \\
\hline 2010 & 0,076 & 0,938 & 0,889 & 0,106 \\
\hline 2011 & 0,060 & 0,964 & 0,935 & 0,071 \\
\hline 2012 & 0,078 & 0,951 & 0,912 & 0,094 \\
\hline 2013 & 0,014 & 0,913 & 0,843 & 0,128 \\
\hline 2014 & 0,086 & 0,937 & 0,887 & 0,107 \\
\hline
\end{tabular}

Fonte: Elaboração do autor

A partir dos parâmetros estabelecidos na Tabela 5, as equações apresentaram ajustes aceitáveis para um modelo exploratório em praticamente todos os anos, exceto 2009 e 2012, quando os valores do RMSEA superaram muito o limite de $10 \%$, com reflexos no GFI e AGFI, que ficaram abaixo de $93 \%$ e $90 \%$, respectivamente. Não obstante, aponta-se para uma fragilidade no ajuste nos anos de 2003, 2004, 2010 e 2014, quando os testes do RMSEA estiveram levemente superiores ao limite de $10 \%$.

Em que pese todos os cuidados empreendidos na construção da base e no tratamento das informações discrepantes, não se deve esquecer que as variáveis observáveis reportam indicadores financeiros reais de empresas brasileiras que têm como característica elevada heterogeneidade entre firmas e setores, o que traz, por consequência, aumento na variância e variáveis com fraca distribuição 
normal. Portanto, as análises multivariadas, neste contexto, precisam considerar a originalidade dos dados tal qual se apresentam (HAIR Jr. et al., 2005).

Em tempo, mesmo com as limitações, assinala-se para um ajuste totalmente adequado das equações estruturais em nove anos, o que permite aceitar a proposição do modelo de análise da dinâmica do endividamento das firmas no Brasil congregando informações exógenas e endógenas.

\section{Considerações finais}

O presente estudo alcançou os seus objetivos ao encontrar variáveis internas e externas que influenciaram a decisão de estrutura de capital das empresas nos anos de 1999 a 2014, com uma base de dados de, em média, 995 firmas, listadas na "Balanços Patrimoniais" e BM\&FBOVESPA, utilizando a análise de modelagem de equações estruturais. Contudo, não foi possível decompor o construto estrutura de capital em endividamento de curto e longo prazo, como estava previsto na proposta original.

O Desempenho Financeiro foi o construto que mais obteve significância na Estrutura de Capital das firmas, reiterando a importância dos fatores internos às firmas durante a escolha do endividamento (KAYO e KIMURA, 2011; MARTINS e TERRA, 2014). Nesse aspecto, existiu relevância das variáveis ROI, ROE e MO na composição desse construto, indicando majoritariamente a relação negativa entre todas as métricas e o endividamento. Esse fato denota que quanto melhor for a desenvoltura dos recursos internos da empresa, tanto menos dívidas ela contrai, apontando para pecking order, já que somente com escassez de recursos internos as empresas recorrem a endividamentos (MYERS, 1984).

O Giro do Ativo não apresentou resultados contrários dos previstos anteriormente, de forma que não foi possível considerá-lo uma métrica de Desempenho Financeiro, pois seu agrupamento no modelo foi com as variáveis de Dinâmica da Indústria.

A Razão de Concentração não apresentou relação com a dinâmica da indústria, e, por conseguinte, com as dívidas das empresas como apontado no estudo de Nejad e Wasiuzzaman (2015). Contudo, as métricas de VLO e VRec associaram-se ao construto, que 
demonstrou que o risco de mercado aumenta o endividamento das empresas, já que a DI teve seu comportamento predominantemente positivo com suas métricas e com a estrutura de capital.

No âmbito empresarial, os gestores tendem a buscar fontes de financiamento, principalmente em função de fatores internos à empresa. Contudo, é possível denotar a relação entre os fatores externos às firmas, indicando que eles também afetam a decisão da estrutura de capital, e, desse modo, os administradores devem focar nesses aspectos, além dos indicadores tradicionais de desempenho, para que determinem o endividamento das empresas de forma menos onerosa e mais adequada.

As limitações do estudo compreendem a exclusão dos valores discrepantes da amostra, que poderiam retornar resultados pouco condizentes com a realidade; também existe a restrição temporal, uma vez que o estudo contempla somente quinze anos.

Recomenda-se que futuros estudos abordem outros fatores externos à empresa, identificando novas variáveis indicativas do setor, da economia e do país que possam sinalizar mudanças na estrutura de capital das empresas. Além disso, a abrangência das variáveis de endividamento de curto e longo prazo se faz necessária em um novo estudo.

\section{REFERÊNCIAS}

ADI, T. W. SUHADAK; HADAYANI; S. R.; E RAHAYU, S. M. The Influence of corporate governance and capital structure on risk, financial performance and firm value: a study on the mining company listed in Indonesia stock exchange in 2009-2012. European Journal of Business and Management [S.1.], v. 5, n. 29, p. 200-217, 2013.

AL ANI, M. K.; AL AMRII, M. S. The determinants of capital structure: an empirical study of Omani listed industrial companies. Business: Theory and Practice, Vilnius, v. 16, n. 2, p. 159-167, jun. 2015.

ALBANEZ, T. Efeitos do market timing sobre a estrutura de capital de companhias abertas brasileiras, 257s. 2012. Tese (Doutorado em Controladoria e Contabilidade) - Faculdade de Economia, Administração e Ciências Contábeis, Universidade de São Paulo, Ribeirão Preto, 2012.

ALVES, P. F. P.; FERREIRA, M. F. Capital Structure and Law Around the World. Journal of Multinational Financial Management [S.1.], v. 21, n. 3, p. 119-150, jul. 2011.

ANTONCZYK, R. C.; SALZMANN, A. J. Overconfidence and optimism: The effect of national culture on capital structure. Research in International Business and Finance [S.1.], v. 31, p. 
132-151, may 2014.

ASSAF NETO, A. Finanças Corporativas e Valor, 6. ed. São Paulo: Atlas, 2014.

ASSAF NETO, A.; LIMA, F. G. I.; DE ARAÚJO, A. M. P. Uma proposta metodológica para o cálculo de custo de capital no Brasil. Revista de Administração, São Paulo, v. 43, n. 1, p. 72-83, jan./fev./mar. 2008.

BALAKRISHANAN, S.; E FOX, I. Asset specificity, firm heterogeneity and capital structure. Strategic Management Journal [S.1.], v. 14, n. 1, p. 3-16, jan. 1993.

BARCLAY, M. J.; HEITZMAN, S. M.; E SMITH, C. W. Debt and Taxes: Evidence from the Real Estate Industry. Journal of Corporate Finance [S.1.], v. 20, p. 74-93, apr. 2013.

BHAIRD, C. M.; LUCEY, B. Culture's influences: an investigation of inter-country differences in capital structure. Borsa Istanbul Review, Istanbul, v. 14, n. 1, p. 1-9, mar. 2014.

BRITO, R. D.; LIMA, M. R. A Escolha da Estrutura de Capital sob Fraca Garantia Legal: O Caso do Brasil. Revista Brasileira de Economia, Rio de Janeiro, v. 59, n. 2, p. 177-208, abr./ jun. 2005.

CARVALHAL, A.; LEAL, R. P. The world financial crisis and the international financing of Brazilian companies. Brazilian Administration Review, Rio de Janeiro, v. 10, n. 1, p. 18-39, jan./mar. 2013.

CHANGA, C.; CHEN, X.; LIAOC, G. What are the reliably important determinants of capital structure in China? Pacific-Basin Finance Journal [S.1.], v. 30, p. 87-113, nov. 2014.

CHUNG, Y. P.; NA, H. S.; SMITH, R. How Important is Capital Structure Policy to Firm Survival? Journal of Corporate Finance [S.1.], v. 22, n. 1, p. 83-103, apr. 2013.

COELHO, A. L.; PAVÃO, Y. M.; SEHNEM, S.; ALBERTON, A.; MARCON, R. Estrutura de Capital: Um estudo bibliométrico em produções do Brasil e exterior. Revista de Informação Contábil, Recife, v. 7, n. 1, p. 73-93, jan./mar. 2013.

CORREA, A. C.; BASSO, L. F. C; NAKAMURA, W. T. A Estrutura de Capital das Maiores Empresas Brasileiras: Análise Empírica das Teorias de Pecking Order e Tradeoff, Usando Panel Data. Revista de Administração Mackenzie, São Paulo, v. 14, n. 4, p. 106-133, jul./ago. 2013.

DAL MAGRO, C. B.; DI DOMENICO, D.; TOLEDO FILHO, J. R. Relação dos fatores determinantes da estrutura de capital das empresas listadas na BM\&FBOVESPA. In: SIMPÓSIO DE ADMINISTRAÇÃO DA PRODUÇÃO, LOGÍSTICA E OPERAÇÕES INTERNACIONAIS, 15, 2012. São Paulo. Anais... São Paulo: FGV/SP, 2012, p. 1-16.

DANG, A. A.; HIM, M.; SHIN, Y. Asymmetric Adjustment Toward Optimal Capital Structure: Evidence from a Crisis. International Review of Financial Analysis [S.1.], v. 33, p. 226-242, may 2014.

DURAND, D. Costs of Debt and Equity Funds for Business: Trends and Problems of Measurement. In: BUREAU, U.-N. 1952. New York. CONFERENCE ON RESEARCH IN BUSINESS FINANCE. Anais eletrônicos... New York: NBER, 1952, p. 215-262. Disponível em: <http:// www.nber.org/books/univ52-1>. Acesso em: 20 set. 2015.

FAREED, Z.; AZIZ, S.; NAZ, S.; SHAHZAD, F.; ARSHAD, M.; UMM-E-AMEN. Testing the 
Relationship Between Profitability and Capital Structure of Textile Industry of Pakistan. World Applied Sciences Journal [S.1.], v. 29, n. 5, p. 605-609, may 2014.

FORTE, D.; BARROS, L. A.; NAKAMURA, W. T. Determinants of the capital structure of small and medium sized Brazilian enterprises. Brazilian Administration Review, Rio de Janeiro, v. 10, n. 3, p. 347-369, jul./set. 2013.

FOSU, S. Capital Structure, product market competition and firm performance: Evidence from South Africa. The Quarterly Review of Economics and Finance [S.1.], v. 53, n. 2, p. 140-151, may 2013.

FRANK, M. Z.; GOYAL, V. K. Testing the Pecking Order Theory of Capital Structure. Journal of Financial Economics [S.1.], v. 67, n. 2, p. 217-248, feb. 2003.

GÓMEZ, A. P.; CASTRO, G. A.; ORTEGA, M. F. Determinants of leverage in mining companies, empirical evidence for Latin American countries. Contaduría y Administración, Ciudad Mexico, v. 61, n. 1, p. 26-40, jan./mar. 2016.

GRAHAM, J. R.; LEARY, M. T. A Review of Empirical Capital Structure Research and Directions for the Future. Annual Review of Financial Economics [S.1.], v. 3, p. 309-345, dec. 2011.

HAIR JR., J. F.; ANDERSEN, R. F.; TATHAN, R. I.; BLACK, W. C. Análise Multivariada de Dados. Porto Alegre: Bookman, 2005.

HANDOO, A.; SHARMA, K. A study on determinants of capital structure in India. IIMB Management Review [S.1.], v. 26, n. 3, p. 170-182, sep. 2014.

HARRIS, M.; RAVIV, A. The theory of capital structure. Journal of Finance [S.1.], v. 46, n. 1, p. 297-35, mar. 1991.

HOYOS, A. N.; GARZÓN, E. A. Key factors for the structure of capital in the oilfield services sector in Colombia. Suma de Negocios [S.1.] v. 6, n. 14, p. 147-154, jul./dec. 2015.

INTELLIGENCE AND SECURITY, 10, 2015. Madurai. Proceedings... Kunming: IEEE, 2015, p. $724-728$.

JENSEN, M. C.; MECKLING, W. Theory of the firm: managerial behavior, agency costs, and capital structure. Journal of Financial Economics [S.1.], v. 3, n. 4, p. 305-360, 1976.

KAVESKI, I. D.; DEGENHART, L.; VOGT, M.; E SILVA, T. P. Determinantes da estrutura de capital das empresas de tecnologia da informação brasileiras. Revista Iberoamericana de Ciencia, Tecnología e Sociedad, Buenos Aires, v. 29, n. 10, p. 235-262, may 2015.

KAYO, E. K.; KIMURA, H. Hierarchical determinants of capital structure. Journal of Banking \& Finance [S.1.] v. 35, n. 2, p. 358-371, 2011.

KELLOWAY, E. K. Using LISREL for structural equation modeling. A researcher's guide. Nova Delhi: Sage Publications Inc., 1998.

LIM, N. H-K.; DAS, S.; DAS, A. Diversification strategy, capital structure, and the asian financial crisis (1997-1998): Evidence from Singapore firms. Strategic Management Journal [S.1.], v. 30, n. 6, p. 577-594, 2009.

MANN, S. V.; SICHERMAN, N. W. The agency costs of free cash flow: Acquisition activity and equity issues. Journal of Business [S.1.], v. 64, n. 2, p. 213-227, apr. 1991. 
MARCON, R.; GRZEBIELUCKAS, C.; BANDEIRA-DE-MELLO, R.; MULLER, R. A. O comportamento da estrutura de capital e a performance de firmas brasileiras, argentinas e chilenas. Revista de Gestão USP, São Paulo, v. 14, n. 2, p. 33-48, abr./jun. 2007.

MARTINS, H. C.; TERRA, P. R. S. Determinantes nacionais e setoriais da estrutura de capital na América Latina. Revista de Administração Contemporânea, Curitiba v. 18, n. 5, p. 577597, set./out. 2014.

MATEEV, M.; POUTZIOURIS, P.; IVANOV, K. On the determinants of SME capital structure in Central and Eastern Europe: A dynamic panel analysis. Research in International Business and Finance [S.1.], v. 27, n. 1, p. 28-51, jan. 2013.

MEDEIROS, O. R.; DAHER, C. E. Testando Teorias Alternativas sobre a Estrutura de Capital nas Empresas Brasileiras. Revista de Administração Contemporânea, Curitiba, v. 12, n. 1, p. 177-199, jan./mar. 2008.

MIGUEL, A.;E PINDADO, J. Determinants of capital structure: new evidence from Spanish panel data. Journal of Corporate Finance [S.1.], v. 7, n. 1, p. 77-99, mar. 2001.

MITANI, H. Capital structure and competitive position in product market. International Review of Economics and Finance [S.1.], v. 29, p. 358-371, jan. 2014.

MODIGLIANI, F.; MILLER, M. H. The Cost of Capital, Corporation Finance and the Theory of Investment. The American Economic Review, Nashville, v. 48, n. 3, p. 261-297, jun. 1958.

MODIGLIANI, F.; MILLER, M. H. Corporate income taxes and the cost of capital: a correction. The American Economic Review, Nashville, v. 53, n. 3, p. 433-443, jun. 1963.

MYERS, S. C. The capital structure puzzle. The Journal of Finance [S.1.], v. 39, n. 3, p. 575592, jul. 1984.

MYERS, S. C. Capital Structure. The Journal of Economic Perspectives, Nashville, v. 15, n. 2, p. 81-102, spring 2001.

MYERS, S.; MAJLUF, N. S. Corporate Financing and Investment Decisions When Firms Have Information that Investors do not Have*. Journal of Financial Economics [S.1.], v. 13, n. 2, p. 187-221, 1984.

NAKAMURA, W. T.; MARTIN, D. M. L.; FORTES, D.; CARVALHO FILHO, A. F.; COSTA, A. C. F.; AMARAL, A. C. Determinantes de Estrutura de Capital no Mercado Brasileiro: Análise de Regressão com Painel de Dados no Período 1999-2003. Revista Contabilidade e Finanças - USP, São Paulo, v. 18, n. 44, p. 72-85, mai./ago. 2007.

NEJAD, N. R.; WASIUZZAMAN, S. Multilevel Determinants of Capital Structure: Evidence from Malaysia. Global Business Review, Nova Delhi, v. 16, n. 2, p. 199-212, apr. 2015.

NOULAS, A.; GENIMAKIS, G. The determinants of capital structure choice: evidence from Greek listed companies. Applied Financial Economics [S.1.], v. 21, n. 6, p. 379-387, jan. 2011.

ÖZTEKIN, Ö. Capital Structure Decisions around the World: Which Factors Are Reliably Important? Journal of Financial and Quantitative Analysis [S.1.], v. 50, n. 3, p. 301-323, jun. 2015.

PEROBELLI, F. F. C.; FAMÁ, R. Fatores Determinantes da Estrutura de Capital para Em- 
presas Latino-Americanas. Revista de Administração Contemporânea, Curitiba, v. 7, n. 1, p. 9-35, jan./mar. 2003.

PHILLIPS, P. A.; SIPAHIOGLU, M. A. Performance Implications of Capital Structure: Evidence from Quoted UK Organizations with Hotel Interests. The Service Industries Journal [S.1.], v. 24, n. 5, p. 31-51, jan. 2004.

SALIM, M.; YADAV, R. Capital Structure and Firm Performance: Evidence from Malaysian Listed Companies. Procedia - Social and Behavioral Sciences [S.1.], v. 65, p. 156-166, dec. 2012.

SANTOS, D. F. L.; FARINELLI, J. B. M. Analysis of Approaches to Capital Structure: A Literature Review. Business and Management Review [S.1.] v. 4, n. 5, p. 290-304, jan. 2015.

SANTOS, D. F. L.; MARTINS, R. A.; FIGUEIRA, S. R. F.; SANCHES, A. Fatores determinantes da estrutura de capital das empresas de materiais básicos do Brasil. Enfoque: Reflexão Contábil, Maringá, v. 33, n. 2, p. 87-103, mai./ago. 2014.

SANTOS, D. F. L.; RODRIGUES, S. V. Desempenho e Estrutura de Capital da Indústria Farmacêutica Brasileira. Estudo e Debate, Lajeado, v. 21, n. 1, p. 7-25, jan./jun. 2014.

SCHUMACKER, R. E.; LOMAX, R.G. A beginner's guide to structural equation modeling. Mahwah: Lawrence Erlbaum Associates Inc., 2004.

SHEIKH, N. A.; WANG, Z. The impact of capital structure on performance: An empirical study of non-financial listed firms in Pakistan. International Journal of Commerce and Management [S.1.], v. 23, n. 4, p. 354-368, 2013.

SIMERLY, R. L.; LI, M. Environmental dynamis, capital structure and performance: a theoretical integration and an empirical test. Strategic Management Journal [S.1.], v. 21, n. 1, p. 31-49, jan. 2000.

TITMAN, S.; WESSELS, R. The Determinants of Capital Structure Choice. The Journal of Finance [S.1.], v. 43, n. 1, 1-19, mar. 1988.

TOMAZONI, T.; MENEZES, E. A. Estimativa do custo de capital de empresas brasileiras de capital fechado (sem comparáveis de capital aberto). Revista de Administração, São Paulo, v. 37, n. 4, p. 38-48, out./dez. 2002.

TUDOSE, M. B. Methodology of research on the factors determining firm's capital structure. Revista de Management şi Inginerie Económicã, Cluj, v. 11, n. 3, p. 145-156, jul./sep. 2012.

TURRA, S.; VERGINI, D. P.; DA CUNHA, P. R. Influência da governança corporativa e da estrutura de capital sobre risco, desempenho financeiro e valor de mercado. In: Simpósio de Administração da Produção, Logística e Operações Internacionais. 18, 2015, São Paulo. Anais... São Paulo: FGV-SP, 2015, p. 1-17.

VIEIRA, E. Determinantes da estrutura de capital das empresas portuguesas cotadas. Revista Portuguesa e Brasileira de Gestão, Lisboa v. 12, n. 1, p. 37-51, jan. 2013.

WILLIAMSON, O. E. The Economic Institutions of Capitalism: Firms, Markets, Relational Contracting. New York: Free Press, 1985.

WONG, K. P. A Regret Theory of Capital Structure. Finance Research Letters [S.1.], v. 12, p. 48-57, feb. 2015. 
XU, Q.; LI, C. An empirical study on determinants of capital structure in chinese listed companies. In: INTERNATIONAL CONFERENCE ON COMPUTATIONAL

YOGENDRARAJAH, R., E THANABALASINGAM, S. The effect of profit margin on capital structure: a study of listed manufacturing companies of Colombo Stock Exchange (CSE). In: Internacional Conference University of Kelaniya, 2011. Proceeding... Colombo: SSRN, 2011, p. 724-728.

Recebido em: 6-7-2017

Aprovado em: 30-8-2017

Avaliado pelo sistema double blind review.

Editor: Elmo Tambosi Filho

Disponível em http://mjs.metodista.br/index.php/roc 